OPEN ACCESS

Platinum Nanoarrays Directly Grown onto a 3D-Carbon Felt Electrode as a Bifunctional Material for Garden Compost Microbial Fuel Cell

To cite this article: Widya Ernayati Kosimaningrum et al $2021 \mathrm{~J}$. Electrochem. Soc. 168025501

View the article online for updates and enhancements.

\title{
Discover the EL-CELL potentiostats
}

- Fully independent test channels with Pstat / GStat / EIS

- Optionally with integrated temperature controlled cell chamber

- Unique Connection Matrix: Switch between full-cell and half-cell control at runtime

www.el-cell.com +49 (0) 4079012734 sales@el-cell.com

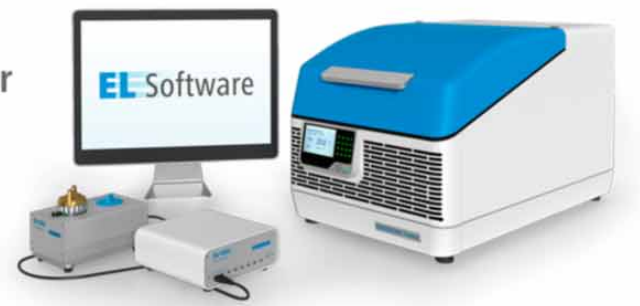




\title{
(ESS) \\ Platinum Nanoarrays Directly Grown onto a 3D-Carbon Felt Electrode as a Bifunctional Material for Garden Compost Microbial Fuel Cell
}

\author{
Widya Ernayati Kosimaningrum, ${ }^{1,2,3}$ Mekhaissia Ouis, ${ }^{1,4}$ Yaovi Holade, ${ }^{1, *, z_{\text {(i) }}}$ \\ Buchari Buchari, ${ }^{2}$ Indra Noviandri, ${ }^{2}$ Mostefa Kameche, ${ }^{4}$ Marc Cretin, ${ }^{1}$ and \\ Christophe Innocent ${ }^{1}$ \\ ${ }^{1}$ Institut Européen des Membranes, IEM-UMR 5635, Univ Montpellier, ENSCM, CNRS, Montpellier, France \\ ${ }^{2}$ Analytical Chemistry Division, Faculty of Mathematics and Natural Sciences, Institut Teknologi Bandung, Bandung, \\ Indonesia \\ ${ }^{3}$ Department of Chemical Engineering, Sultan Ageng Tirtayasa University, Jl. Jend. Sudirman KM 3, Cilegon, Indonesia \\ ${ }^{4}$ Laboratoire de Physico-Chimie de Matériaux, Catalyse et Environnement, Université de Sciences et de la Technologie \\ d'Oran-Mohammed Boudiaf, Oran, Algérie
}

\begin{abstract}
The practical implementation of air-breathing microbial fuel cell (MFC) is critically linked to the development of efficient materials as cathode and electrochemically active biofilm-based anode. In this contribution, we demonstrate the feasibility by decorating a 3D carbon felt electrode with Pt nanoarrays (CF@Pt) as a bifunctional electrode material as efficient garden compost bioanode and airbreathing cathode. Half-cell electrochemical characterizations reveal that the onset potential of the anode reaction negatively shifts of about $800 \mathrm{mV}$ to reach $-0.4 \mathrm{~V}$ vs $\mathrm{Ag} / \mathrm{AgCl}$ after the growth of the biofilm onto CF@ Pt. The investigation before and after the biofilm formation shows that Pt nanoarrays act as excellent electron relays, reducing significantly the charge transfer resistance. For MFC application (with a proton exchange membrane), the use of CF@Pt as bioanode' scaffold and CF@Pt air-cathode enables a drastically enhanced power density of $\mathrm{P}_{\max }=292.3 \mathrm{~mW} \mathrm{~m}^{-2}$, and a high short-circuit current density $\mathrm{j}_{\mathrm{sc}}=1.9 \mathrm{~A} \mathrm{~m}^{-2}$.

(c) 2021 The Author(s). Published on behalf of The Electrochemical Society by IOP Publishing Limited. This is an open access article distributed under the terms of the Creative Commons Attribution Non-Commercial No Derivatives 4.0 License (CC BYNC-ND, http://creativecommons.org/licenses/by-nc-nd/4.0/), which permits non-commercial reuse, distribution, and reproduction in any medium, provided the original work is not changed in any way and is properly cited. For permission for commercial reuse please email: permissions@ ioppublishing.org. [DOI: 10.1149/1945-7111/abde7c]
\end{abstract}

Manuscript submitted October 30, 2020; revised manuscript received December 28, 2020. Published February 1, 2021.

Supplementary material for this article is available online

Cogeneration devices that, in addition to their primarily role, enable the realization of a secondary task have historically been a hot topic of research. ${ }^{1-7}$ Specifically, microbial fuel cells (MFCs) that have emerged as a class of electrochemical devices with the ability of wastewater treatment, pollutant removal and concomitant net electrical energy harvesting from organic wastes are a typical example of cogeneration devices. ${ }^{4,8-16}$ Basically, the operation of MFCs needs electrochemically active biofilms that host certain bacteria for the organic matters degradation at an electrode so-called bioanode. Termed as cathode, the electron acceptor is typically an abiotic material, ranging from electroactive components such as platinum $(\mathrm{Pt})$ for oxygen reduction reaction (ORR) to stainless steel plate dipped inside a ferricyanide solution. ${ }^{11,13-19}$ To date, two configurations in which electrodes face many limitations in terms of long-term operation and large-scale applications have been developed, double-chamber MFCs and single-chamber (or air-breathing) MFCs. ${ }^{10,20-25}$

Recently, Gaffney et al. $^{26}$ have reviewed the emerged computational approaches for understanding the microbial electrochemical systems in order to derive general designing principles. Some factors related to anode material such as biocompatibility, stability, surface area, conductivity, and charge transfer resistance should be considered to provide an optimal environment for the growth of the electroactive biofilm. Various types have been explored, especially carbon based materials such as carbon felt, carbon cloth, graphite felt, graphite rod, graphite granules and activated carbon. ${ }^{11}$ In addition to its excellent biocompatibility, the use of carbon felt as anode material enables maximizing the amount of electroactive species owing to its tridimensional (3D) structure. However, the pristine material exhibits high hydrophobicity that could contribute to a relatively high resistance and low performance. In order to improve the bacterial adhesion and increase the extracellular

*Electrochemical Society Member.

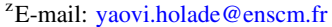

electron transfer, various tactics have been adopted. ${ }^{21,27}$ The incorporating of nanoscale materials seems promising to provide better interactions with biological systems due to the close dimension, special electronic properties, and parades as a good strategy to enhance the electrochemically active surface area and spread up the kinetics. ${ }^{27-29}$ Combined with a flow and double-chamber MCF, the strategy improves significantly the performance, as noticed by Zhang et al. ${ }^{27}$ They obtained a maximum power density of $\sim 2000 \mathrm{~mW} \mathrm{~m}^{-2}$ for a bioanode made of reduced graphene oxide and manganese nanocomposites on carbon felt, which was $154 \%$ higher than that with a bare anode. We have previously demonstrated that a surfactant- and binder-free hierarchical nanostructured Pt can provide best up performance and longevity as an air-breathing cathode. $^{21}$ To date, there are still key and unanswered questions about the electronic transfer capacity and the growth of electroactive biofilms when nanoparticles decorate the fibers of a 3D network. This kind of investigation is important to advance the field towards the achievement of high electrical performance with MFCs. In this work, we examine the design of a garden compost MFC system wherein metallic particles will simultaneously act as bridge between the biofilm and its electrode' scaffolds, and an electrocatalytic interface for ORR via air-breathing cathode. To date, this type of bifunctional materials composed of Pt nanoarrays directly grown onto an electroactivated carbon felt $(\mathrm{CF} @ \mathrm{Pt})$ has not been reported for the targeted application as bioanode in MFCs. Complementary electroanalytical methods of cyclic voltammetry (CV), linear voltammetry (LSV), and electrochemical impedance spectroscopy (EIS) were tightly combined to interrogate the processes taking place at the cathode and the anode.

\section{Experimental}

Chemicals and materials.-Three-dimensional carbon felt electrode (6.35 mm thick, 99\%) was obtained from Alfa Aesar. Sulfuric acid $\left(\mathrm{H}_{2} \mathrm{SO}_{4}, 97 \%\right)$, ethanol (VWR, 96\%), hexahydrate hexachloroplatinic (IV) acid $\left(\mathrm{H}_{2} \mathrm{PtCl}_{6} \cdot 6 \mathrm{H}_{2} \mathrm{O}, 99 \%\right)$, and potassium chloride 
$(\mathrm{KCl}, 99 \%)$ were purchased from Sigma-Aldrich. Sodium acetate (99\%, Carlo Erba Reagents), and garden compost (Neuhaus) were used as received. A Milli-Q Millipore source was used to produce ultrapure water $\left(18.2 \mathrm{M} \Omega \mathrm{cm}\right.$ at $\left.20^{\circ} \mathrm{C}\right)$.

Activation of $3 D$ carbon felt electrodes.-The carbon felt electrode $(\mathrm{CF})$ is hydrophobic so that tentative tests to deposit a significant amount of $\mathrm{Pt}$ particles failed. ${ }^{21}$ So, CF was electrochemical activated prior to use. Basically, a sample was cut into a L-shape of $4 \mathrm{~cm}$ height, $1 \mathrm{~cm}$ width, and $0.635 \mathrm{~cm}$ thickness. Enough space was left on the upper side for electrical connection with a gold wire. By not taking into account the internal area, the estimated geometric area is $13.7 \mathrm{~cm}^{2}$. The sample underwent an ultrasonic cleaning step (water bath) with ethanol ( $2 \mathrm{~h}$ ). It was then thoroughly washed with ultrapure water, and dried in an oven at $70{ }^{\circ} \mathrm{C}$ for $12 \mathrm{~h}$. Then, the electrode was connected to as working electrode for activating in $1 \mathrm{M} \mathrm{H}_{2} \mathrm{SO}_{4}$ by the method of $\mathrm{CV}$. The counter electrode was a stainless steel plate. The reference electrode was a saturated silver/silver chloride $(\mathrm{Ag} / \mathrm{AgCl})$. The used potentiostat was SP-50 from Biologic Science Instruments and the utilized program was 30 cycles at $20 \mathrm{mV} \mathrm{s}^{-1}$ between 0 and $1.5 \mathrm{~V}$ vs $\mathrm{Ag} / \mathrm{AgCl}$. Finally, the electrode was copiously rinsed with ultrapure water until neutral $\mathrm{pH}$ before drying at $70{ }^{\circ} \mathrm{C}$ overnight.

Electrochemical growth of Pt nanoarrays onto $3 D$ CF.-The preparation of Pt-modified CF followed the optimized conditions of our previous work. ${ }^{21}$ Typically, the above three-electrode configuration was used. Electrodeposition was performed at $-0.60 \mathrm{~V}$ vs $\mathrm{Ag} / \mathrm{AgCl}$ (i.e., $0.14 \mathrm{~V}$ vs reversible hydrogen electrode (RHE) at $\mathrm{pH}$ 9) for $1 \mathrm{~h}$ under $\mathrm{N}_{2}$ atmosphere. The potential was fixed higher than $0 \mathrm{~V}$ vs RHE in order to suppress immediately any formed $\mathrm{H}_{2}$ during the process. The as-fabricated material was referred to as $\mathrm{CF} @ \mathrm{Pt}$.

Characterization of the electrodes by scanning electron microscopy (SEM).- The materials that were not modified by the biofilm were directly analyzed by SEM on a Hitachi S-4800 microscope to gain textural and morphological insights. For the materials with biofilm, i.e., the bioanode samples, they were firstly pretreated to strengthen biofilm attachment and to remove water. Typically, a small piece of bioanode $(0.5 \times 0.5 \times 0.635 \mathrm{~cm})$ was immersed in 4 wt. $\%$ of a glutaraldehyde solution for $4 \mathrm{~h}$. Then, the sample was carefully rinsed with ultrapure water. Dehydration process was carried out by the maceration of the sample in a series of graded concentration of ethanol solution $(20,40,60,80$, and $98 \mathrm{wt} \%)$ for $10 \mathrm{~min}$ in each concentration. Finally, the sample was dried in a desiccator at room temperature for $24 \mathrm{~h}$ before analysis by SEM.

Electrochemical characterization of the anode under MFC configuration.- Half-cell polarization of the anode at the different stages of biofilm growth was recorded in either a double-chamber MFC system or a single-chamber MFC one. Both operated under a switchable configuration of three or two electrodes thanks to the ON/ OFF mode of the reference electrode (RE). A Nafion 115 was used as the proton exchange membrane (PEM) and was activated overnight in water prior to use. For both configurations, the inoculum source was the garden compost leachate obtained by lixiviation. Garden compost and $60 \mathrm{mM}$ potassium chloride solution (equivalent volume ratio of 1:1) were mixed and stirred for $24 \mathrm{~h}^{21,30}$ After the filtration on a sieve, a garden compost leachate was recovered followed by the addition of sodium acetate (final concentration = $20 \mathrm{mM}$ ). Double-chamber configuration utilizes a large surface area stainless steel plate as the counter electrode (in contact with $20 \mathrm{mM}$ potassium ferricyanide solution), $\mathrm{Ag} / \mathrm{AgCl}$ reference electrode, and scrutinizes 3 working electrodes (CF $\left(20 \mathrm{~cm}^{2}\right), \mathrm{CF} @ \mathrm{Pt}\left(14 \mathrm{~cm}^{2}\right)$, and bare graphite $\left.\left(\mathrm{GB}, 13 \mathrm{~cm}^{2}\right)\right)$. The current density was based on the estimated geometric surface area of each electrode. Singlechamber utilizes a CF@Pt anode connected to as working electrode, an $\mathrm{Ag} / \mathrm{AgCl}$ reference electrode, and $\mathrm{CF} @ \mathrm{Pt}$ air-breathing cathode connected to as counter electrode. To prepare the latter, Nafion 115 PEM and CF@Pt electrode were pressed together to leave $3.14 \mathrm{~cm}^{2}$ as exposed surface area. PEM orientated towards the anodic solution and CF@Pt is directly exposed to the surrounding air in the room. The methods of CV, LSV, and EIS were used for the electrochemical characterization.

Electrochemical characterization of the air-breathing cathode under MFC configuration.-For the half-cell polarizations of the air-breathing, the above conditions using single-chamber microbial fuel cell system were utilized to probe different materials $(\mathrm{CF}$, and $\mathrm{CF} @ \mathrm{Pt})$ connected to as working electrode. This air-breathing cathode was prepared by the above procedure to fix Nafion 115 PEM to CF or CF@Pt. The characterization methods were CV, LSV, and EIS. The current was normalized by the exposed surface area, which is $3.14 \mathrm{~cm}^{2}$.

MFC testing.-The content of each compartment is identical to the previous descriptions. To grow the biofilm, a resistance of $\mathrm{R}=$ $1 \mathrm{k} \Omega$ was connected to the MFC. The electrical characteristics of the MFC were recorded by utilizing the technique of "constant resistance discharge." Variable external resistances from $2 \mathrm{M} \Omega$ to $10 \Omega$ were applied to the MFC; it is important to start by the high resistance where the cell voltage is roughly that of the open circuit voltage $(\mathrm{OCV})$. After a few minutes of stabilization, the current and power were derived from the applied resistance and the measured cell voltage. Then, the current density $\left(\mathrm{j}, \mathrm{A} \mathrm{m}^{-2}\right)$ and power density $\left(\mathrm{P}, \mathrm{W} \mathrm{m}^{-2}\right)$ are obtained after normalizing by the area of the currentlimiting process, i.e., the cathode. The MFC was also characterized by EIS at OCV's conditions (see text).

\section{Results and Discussion}

Developed setup for microbial fuel cell scrutinizing.-Different cell and electrode configurations were designed to provide relevant information about the operation of each bio-electrocatalytic process. Figures $1 \mathrm{a}-1 \mathrm{~b}$ sketch the designed setup including a reference electrode (RE) to probe the potential of each electrode during the fuel cell operation, and a connected resistance $R=1 \mathrm{k} \Omega$ to grow the biofilm. To have a better baseline performance, we run control experiments with other materials, as recommended by Logan et al. ${ }^{11}$ The cathodic reaction occurring in a conventional double-chamber MFC (Fig. 1a) is the redox process $\mathrm{Fe}(\mathrm{CN})_{4}{ }^{3-}+1 \mathrm{e}^{-} \rightarrow \mathrm{Fe}(\mathrm{CN})_{4}{ }^{4-}$. This means that the ferricyanide should be either continuously supplied or regenerated. The first scenario in practically unrealistic because it will require an excessively high amount of this harmful compound. The second option of regeneration could, in principle, work given that the redox couple $\mathrm{Fe}(\mathrm{CN}){ }_{4}{ }^{3-} / \mathrm{Fe}(\mathrm{CN})_{4}{ }^{4-}$ has fast kinetics on a large number of electrodes. However, this would mean that one has to stop the operation of the MFC for a certain time in order to make the regeneration. The other major issue about this regeneration option is that when the concentration of the ferricyanide falls below a certain limit, it will negatively impact the performance of the MFC. Then, the alternative is to use the unlimited amount of $\mathrm{O}_{2}$ from the air as the electron acceptor. However, running that by a direct bubbling into a solution leads to low efficiency and a heavy system so that air-breathing cathode strategy (Fig. 1b) is the best option. Hence, we examined the 2-layered and 3-layered strategy for the biofilm fabricating (Fig. 1c), hypothesizing that the interacted platinum particles will provide positive effect by accelerating the electrons transfer between the bare electrode $(\mathrm{CF})$ and the formed biofilm.

Physicochemical characterization of the electrodes.-The SEM images of such materials (GB, CF, and CF@Pt) before and after the biofilm formation are shown on Figs. 2a-2f. Additional SEM images of CF@Pt are reported in Fig. S1 (available online at stacks.iop.org/ JES/168/025501/mmedia). The used CF is made of fibers with a size of 15-20 $\mu \mathrm{m}$. Furthermore, it can be observed that platinum particles 
a

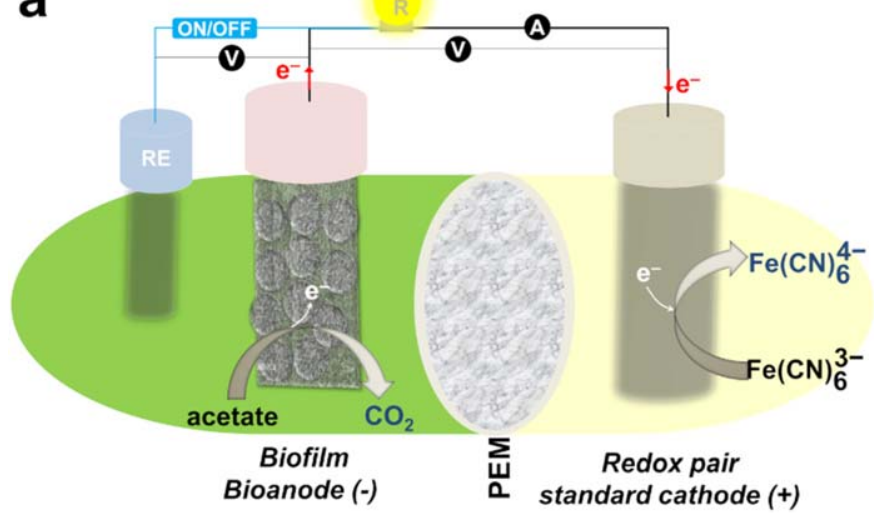

b

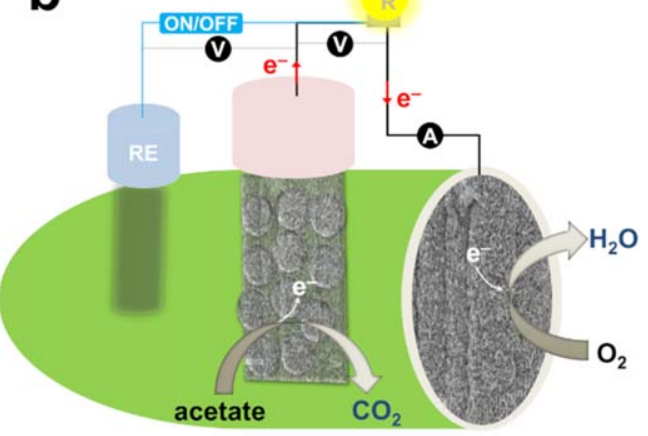

Biofilm

Bioanode (-)

C

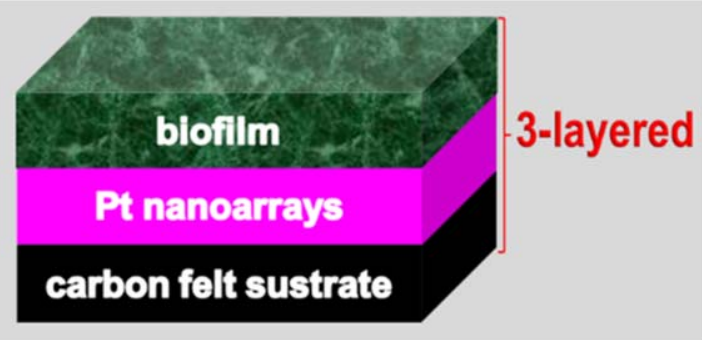

Figure 1. Designed systems for the microbial fuel cell (MFC) testing and scrutinizing. (a) Experimental set-up for half-cell electrochemical measurements for MFC in conventional double-chamber. (b) Experimental set-up for MFC in the configuration of air-breathing cathode. (c) The two approaches for fabricating an active bioanode: without platinum nanoarrays (left side) and with platinum nanoarrays (right side). A load of $\mathrm{R}=1 \mathrm{k} \Omega$ was used for the biofilm growth when the reference electrode $(\mathrm{RE})$ is switched OFF.
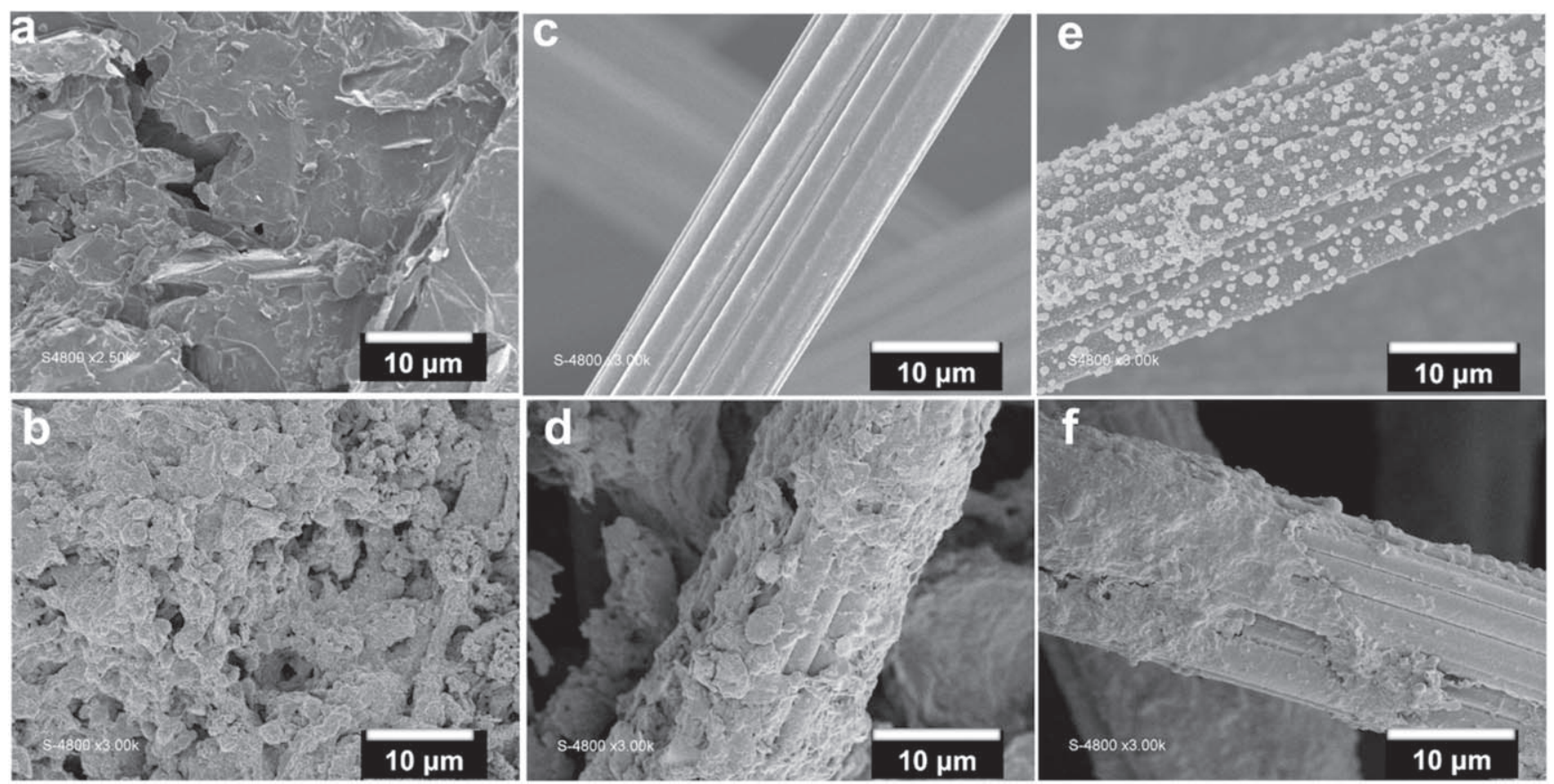

Figure 2. SEM images of: (a) GB without biofilm, (b) GB with biofilm, (c) CF without biofilm, (d) CF with biofilm, (e) CF@ Pt without biofilm, and (f) CF@ Pt with biofilm.

with nanoscale domains (Fig. 2e) are well-dispersed on the carbon felt electrode. The particles size is, however, heterogeneous, from small nanoparticles of $10-50 \mathrm{~nm}$ to microparticles of $0.1-1 \mu \mathrm{m}$ with a rough surface. Such heterogeneity could contribute to the formation and the anchoring/tethering of high amount of electrocatalytic biofilm. Figures $2 \mathrm{~b}, 2 \mathrm{~d}$ and $2 \mathrm{f}$ show that the bacteria colonized the entire surface of the electrodes. Owing to its 3D structure and the presence of $\mathrm{Pt}$ particles, the biofilm modification of $\mathrm{CF} @ \mathrm{Pt}$ is expected to bring significant enhancement in terms of the bioelectrocatalytic activity. 
Electrochemical characterization in half-cell.-Having revealed the microscopic structure of these potential electrodes, we next sought to examine carefully and electrochemically their half-cell performance by using CV, and LSV as powerful tools. To mimic the real fuel cell operation, we designed an in situ garden compost MFC system in which CV and LSV are performed. Figures 3a-3c display the CVs recorded at $10 \mathrm{mV} \mathrm{s}^{-1}$ for the anode at the different stages of the biofilm formation using a double-chamber MFC. For the singlechamber, the results for CF@Pt and CF@Pt@biofilm are shown in Fig. 3d. The analysis demonstrates an increase in the oxidation current density upon the formation of the biofilm, when the starting material is either GB or CF (Figs. 3a, and 3b). Unlike this observation, the CV profiles in Fig. 3c before and after the biofilm formation substantiate the coverage of CF@Pt by the biofilm because the signals related to protons adsorption and desorption disappear completely. The same observation can be made for the air-breathing cathode configuration in Fig. 3d. This suggests that a potential direct interaction of platinum particles with garden compost solution is inhibited. Given the absence of the characteristic proton adsorption-desorption signal that distinguishes platinum, it can consequently be deduced that the electrocatalytic activity of the CF@Pt@biofilm electrode will be uniquely characteristic of the bacterial culture.
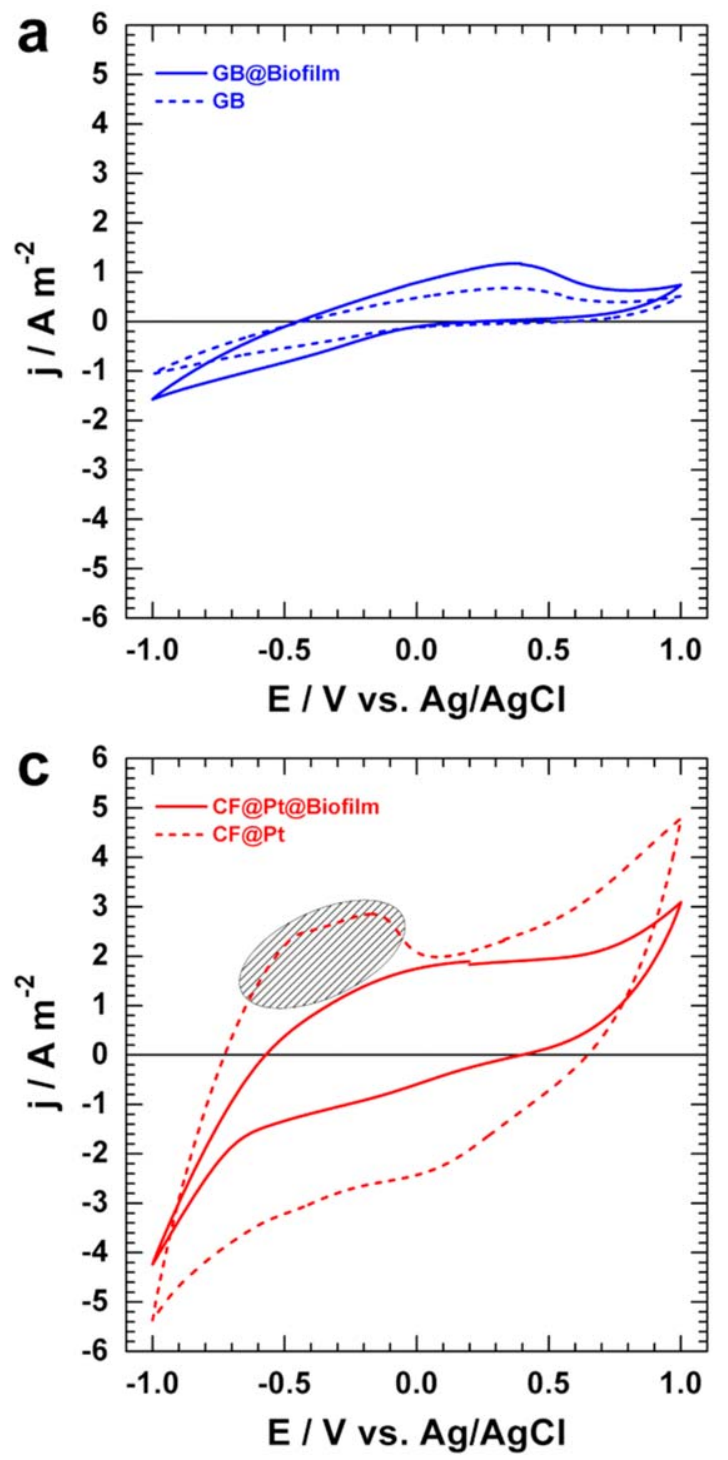

To gain more insights on the MFC operation, the polarization curves of the anode before and after the biofilm formation were recorded by LSV at the low scan rate of $0.005 \mathrm{~V} \mathrm{~s}^{-1}$. The data are shown in Fig. 4a for the double-chamber configuration and those of single-chamber are displayed in Fig. 4b (upper). For the first configuration, we firstly examined the metric of the open circuit potential (OCP) also termed to as $E_{\mathrm{I}=0}$ that theoretically indicates, under thermodynamic regime, the point at which the reaction should start for a rapid system. For all bare anode materials, OCP is +405 , +285 and $-15 \mathrm{mV}$ vs $\mathrm{Ag} / \mathrm{AgCl}$ for $\mathrm{CF} @ \mathrm{Pt}, \mathrm{GB}$, and $\mathrm{CF}$ respectively. These relatively high values are related to the dissolved $\mathrm{O}_{2}$ in the beginning of the MFC operation, which is particularly true for any solution that is in contact with atmospheric air. ${ }^{31,32}$ The high value of $\mathrm{OCP}=0.4 \mathrm{~V}$ vs $\mathrm{Ag} / \mathrm{AgCl}$ for $\mathrm{CF} @ \mathrm{Pt}$ confirms that the as-deposited platinum particles are electrocatalytically active to catalyze ORR. The standard redox potential of the couple $\mathrm{Fe}(\mathrm{CN})_{4}{ }^{3-} / \mathrm{Fe}(\mathrm{CN})_{4}{ }^{4-}$ being $\sim 0.2 \mathrm{~V}$ vs $\mathrm{Ag} / \mathrm{AgCl}$, it means that without biofilm no significant cell voltage $\left(\mathrm{E}_{\text {cell }}=\mathrm{E}_{\text {cathode }}-\mathrm{E}_{\text {anode }}\right)$ can be extracted. After the biofilm formation (roughly three weeks later), anode's OCP shifts toward lower potentials to be $-400,-175$ and -390 mV vs Ag/AgCl for CF@Pt@biofilm, GB@biofilm, and CF@biofilm respectively. The results highlight an improvement of
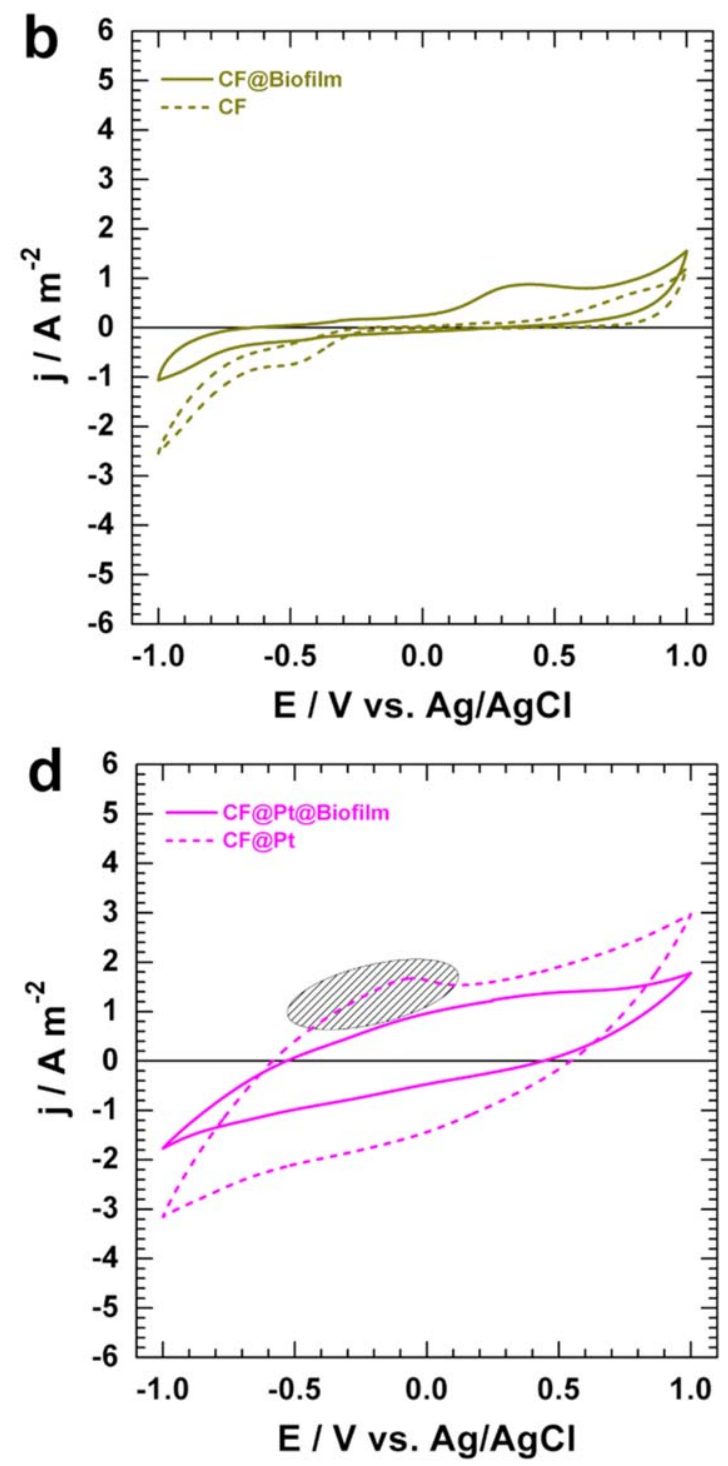

Figure 3. (a)-(c) $\mathrm{CVs}$ recorded at $10 \mathrm{mV} \mathrm{s}^{-1}$ for the anode at the different stages of the biofilm formation in a double-chamber MFC: (a) GB (dimensions: $4 \times$ $\left.1 \times 0.5 \mathrm{~cm}: 12.5 \mathrm{~cm}^{2}\right)$, (b) CF $\left(6 \times 1 \times 0.635 \mathrm{~cm}: 20.2 \mathrm{~cm}^{2}\right)$, and (c) CF@ Pt $\left(4 \times 1 \times 0.635 \mathrm{~cm}: 13.7 \mathrm{~cm}^{2}\right)$. (d) CV recorded at $10 \mathrm{mV} \mathrm{s}$ at the different stages of the biofilm formation in a single-chamber MFC: CF@Pt anode $\left(4 \times 1 \times 0.635 \mathrm{~cm}: 13.7 \mathrm{~cm}^{2}\right)$, and CF@Pt air-breathing cathode. 

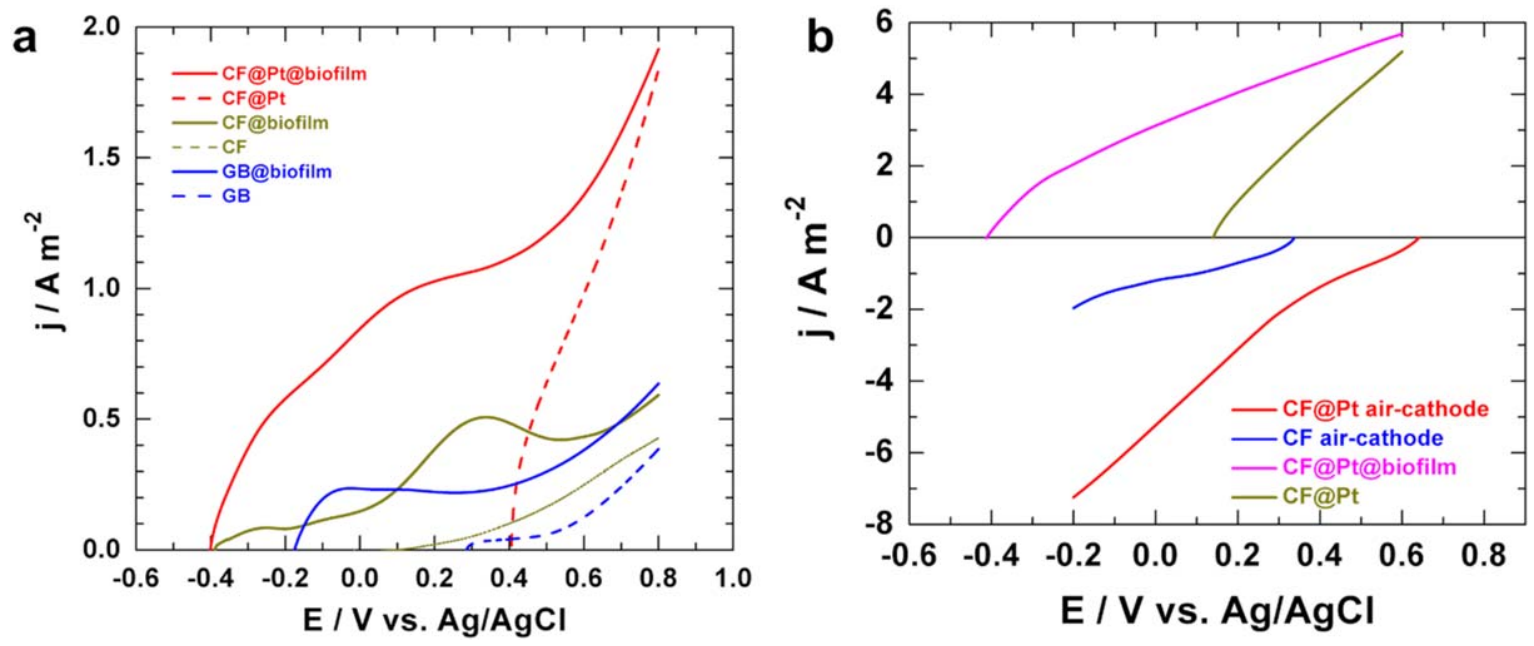

Figure 4. Half-cell polarization curves recorded at $0.005 \mathrm{~V} \mathrm{~s}^{-1}$ in garden compost leachate + acetate. (a) Different anodes in a double-chamber MFC. (b) Airbreathing MFC: anode (up: $\mathrm{j} \geqslant 0$ ), and cathode (down: $\mathrm{j} \leqslant 0$ ).

the OCP for 3D carbon felt electrode in comparison to the bare graphite plate with a downshift of $200 \mathrm{mV}$. While the GB@biofilm's OCP does not change significantly, it is worth of noting that the OCP of CF-based materials are remarkably approaching the theoretical value of sodium acetate oxidation, i.e. $-496 \mathrm{mV}$ vs $\mathrm{Ag} / \mathrm{AgCl}^{31}$ The negative values of OCP suggest the electroactivity of the bioanode as well as the anaerobic condition. ${ }^{31,33}$ OCP by itself is not sufficient to judge the ability of an electrode to drive proficiently an electrochemical reaction and deliver high currents under realistic conditions. So, by examining the current densities at an electrode potential $\mathrm{E}>\mathrm{OCP}$ in Fig. 4a, the composite electrode referred to as CF@Pt@biofilm has fast a bio-electrocatalytic kinetic to achieve high current densities a low overpotential. For instance, $1 \mathrm{~A} \cdot \mathrm{m}^{-2}$ can be achieved for CF@Pt@biofilm at ca.0.2 V vs Ag/AgCl whereas no other tested electrode allows that so far.

We subsequently turned out our switchable configuration of three/two electrodes design to examine the single-chamber MFC. The LSV profiles of the anode in Fig. $4 b$ (upper side) clearly point out that CF@Pt@biofilm ( $\mathrm{OCP}=-0.41 \mathrm{~V}$ vs $\mathrm{Ag} / \mathrm{AgCl})$ as bioanode outperforms $\mathrm{CF} @ \mathrm{Pt}(\mathrm{OCP}=0.14 \mathrm{~V}$ vs $\mathrm{Ag} / \mathrm{AgCl})$. It comes up that not only the biofilm formation is more facilitated at the surface of CF@Pt but also leads to an electrode with high current densities compared to its counterpart. For the cathode reaction of oxygen reduction (Fig. 4 b, down side), the achieved OCP of 0.3 and $0.6 \mathrm{~V}$ vs $\mathrm{Ag} / \mathrm{AgCl}$ for $\mathrm{CF}$, and $\mathrm{CF} @ \mathrm{Pt}$, respectively, demonstrates that Pt nanoarrays are still electrocatalytically active even if the anode compartment (garden compost + acetate + potassium chloride) contains highly poisoning species that could interferences. Kinetically, the LSV shows a significantly higher ORR's performance for CF@Pt air-breathing cathode due to the contribution of Pt active sites. From those set of results, it can be lastly concluded that CF@Pt could act as an excellent multifunctional material for use as both air-cathode for abiotic $\mathrm{O}_{2}$ reduction into $4 \mathrm{e}^{-}$(previously verified ${ }^{21}$ ) and interfacial substrate for efficient bacterial colonization for the bioelectrocatalytic organic matters oxidation. The Pt loading was determined to be lower than $0.2 \mathrm{mg} \mathrm{cm}^{-2}$, which should justify the integration into practical air-breathing MCF as electrode material.

Microbial fuel cell testing.-We next performed the fuel cell tests to verify whether the observed trends in half-cell hold in real situation or not. For that, based on the previous findings, the electrical performance was firstly recorded for the double-chamber configuration for the three types of bioanode, i.e., GB@biofilm, CF@biofilm, and CF@Pt@biofilm. Figure 5a shows the obtained results. The OCV values are 0.49,0.69, and 0.68 V for GB@biofilm, CF@biofilm, and CF@Pt@biofilm, respectively. These data confirm the previous evolution of the OCP. For the electrical metrics, the performance decreases in the order CF@Pt@biofilm $\left(\mathrm{P}_{\max }=121.6 \mathrm{~mW} \mathrm{~m}^{-2}, \mathrm{j}_{\mathrm{sc}}=\right.$ $\left.0.66 \mathrm{~A} \mathrm{~m}^{-2}\right)>\mathrm{CF} @$ biofilm $\left(\mathrm{P}_{\max }=51.4 \mathrm{~mW} \mathrm{~m}^{-2}, \mathrm{j}_{\mathrm{sc}}=0.41 \mathrm{~A} \mathrm{~m}^{-2}\right)$ $>$ GB@biofilm $\left(\mathrm{P}_{\max }=31.1 \mathrm{~mW} \mathrm{~m}^{-2}, \mathrm{j}_{\mathrm{sc}}=0.19 \mathrm{~A} \mathrm{~m}^{-2}\right)$. In other
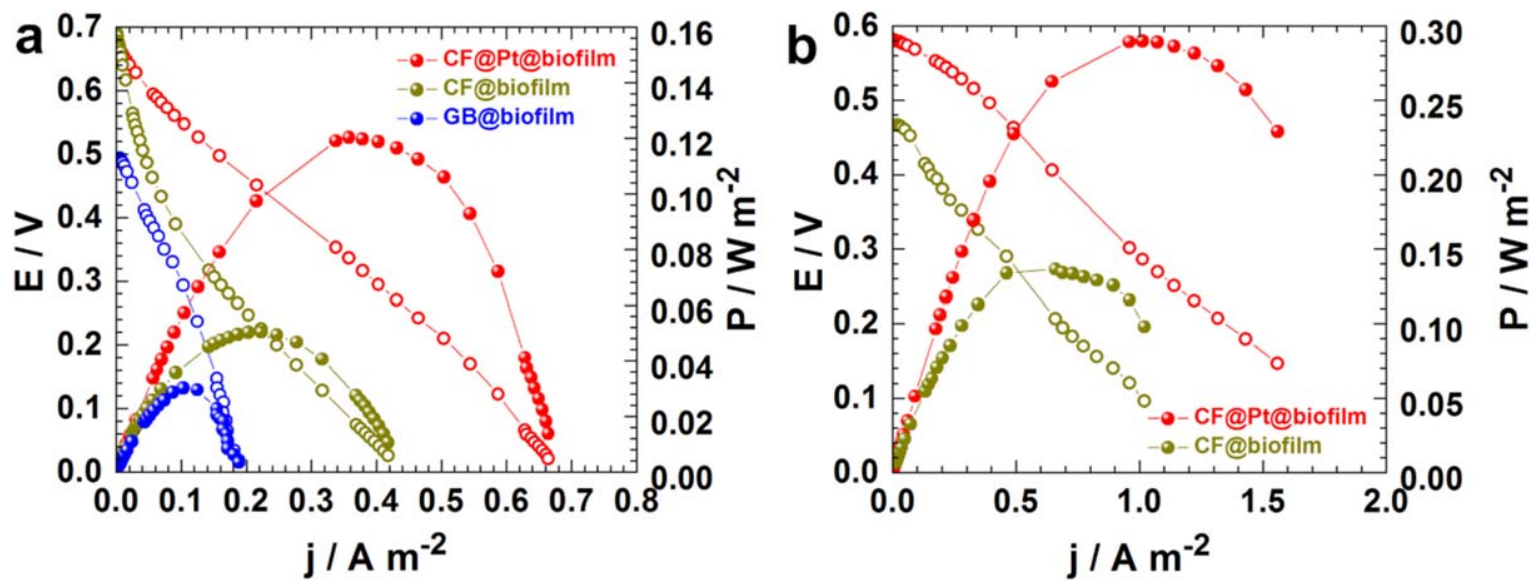

Figure 5. (a) Cell voltage E (opened circles: left $y$-axis), and power density P (full circles: right $y$-axis) of the electrical performance of a double-chamber MFC with the same cathode (stainless steel cathode), and different bioanodes. (b) Cell voltage E (opened circles: left $y$-axis), and Power density P (full circles: right $y$-axis) of the electrical performance of the single-chamber MFC utilizing CF@Pt air-cathode and different bioanodes. Data were iR-drop uncorrected. 

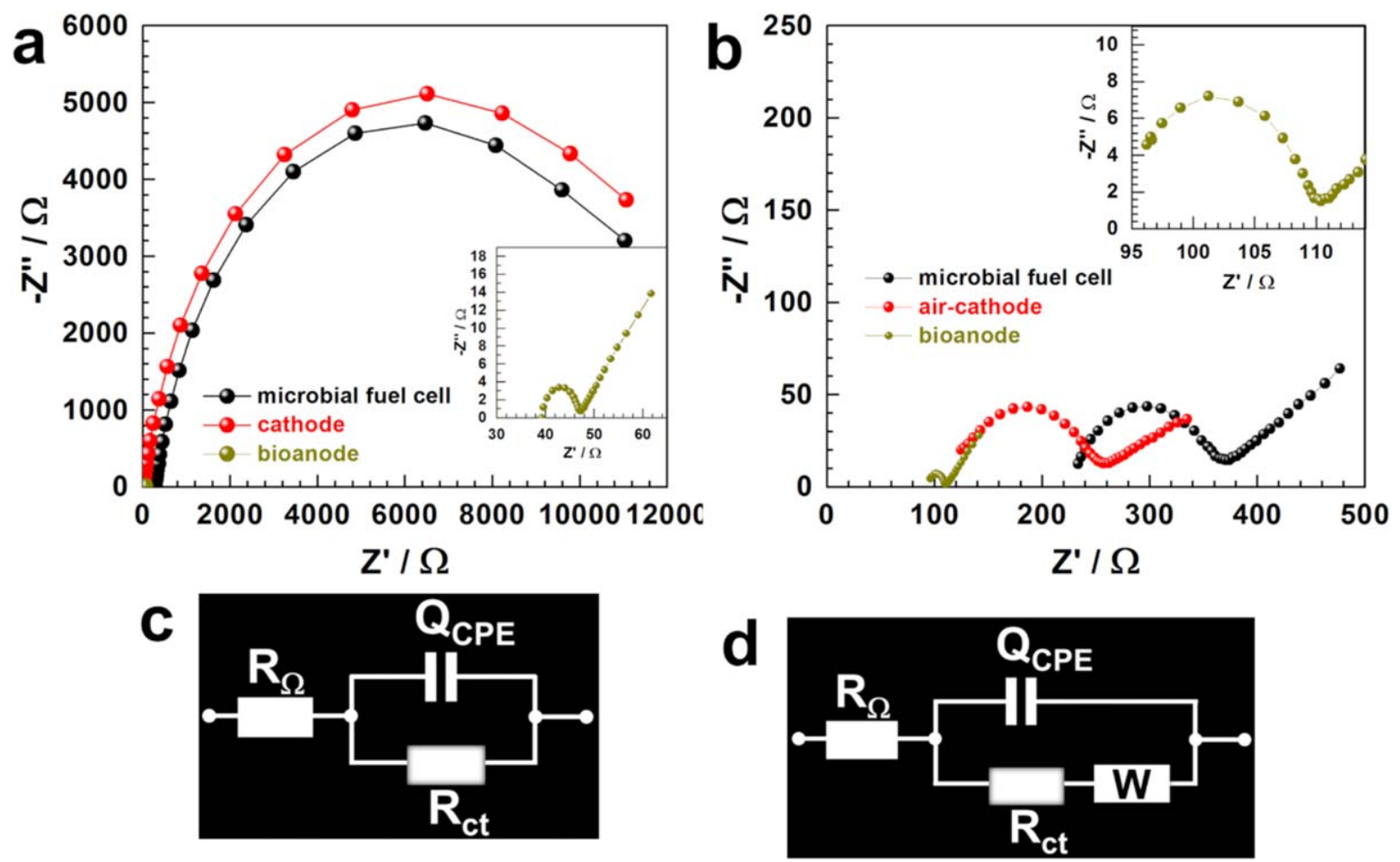

Figure 6. (a) Complex-plane Nyquist impedance plots for a double-chamber MFC at the open circuit conditions: stainless steel=cathode, and CF@Pt@biofilm = bioanode. (b) Complex-plane Nyquist impedance plots at the open circuit for a single-chamber MFC: CF@Pt= air-breathing cathode, and CF@Pt@biofilm= bioanode. (c) Equivalent electrical circuit of $\mathrm{R}_{\Omega}+\mathrm{Q}_{\mathrm{CPE}} / / \mathrm{R}_{\mathrm{ct}}$. (d) Equivalent electrical circuit of $\mathrm{R}_{\Omega}+\mathrm{Q}_{\mathrm{CPE}} / /\left(\mathrm{R}_{\mathrm{ct}}+\mathrm{W}\right)$. Experiments were performed during the growth of the biofilm (load of $\mathrm{R}=1 \mathrm{k} \Omega$ ) and before a fresh fuel is added at current minimum.

words, $\mathrm{P}_{\max }$ was dramatically increased by 2.4 times after inserting $\mathrm{Pt}$ particles between $\mathrm{CF}$ and biofilm. Both CF@biofilm, and CF@Pt@biofilm outperform the GB@biofilm bioanode. Such findings in real fuel cell application are fully consistent with our hypotheses of increased performance upon the growth of platinum particles before the biofilm formation.

To extend the scope and get deeper insights, the best performing CF@Pt@biofilm bioanode was selected to be combined with CF@Pt air-cathode for single-chamber MFC testing. Of course, CF@biofilm was tested as the control bioanode to evidence any key contribution of the 3-layered structure. The results are presented in Fig. 5b. The recorded OCV is ca. $0.6 \mathrm{~V}$ for CF@Pt-based bioanode, which is substantially larger than the value achieved by the control material, $\mathrm{CF}$. The fuel cell metrics of $\mathrm{j}_{\mathrm{sc}}$ and $\mathrm{P}_{\max }$ are $1.9 \mathrm{~A} \mathrm{~m}^{-2}$ and $0.3 \mathrm{~W} \mathrm{~m}^{-2}$, respectively for CF@Pt-based bioanode. The recorded values of $j_{\mathrm{sc}}=1.1 \mathrm{~A} \mathrm{~m}^{-2}$ and $P_{\max }=0.14 \mathrm{~W} \mathrm{~m}^{-2}$ for CF-based bioanode highlight an enhanced electrical performance in the presence of Pt nanoarrays. A sizeable increase in the performance of MFC due to metallic nano-species ( $\mathrm{Pt}, \mathrm{Au}, \mathrm{Mn}, \mathrm{Fe}$, etc) has been widely reported. ${ }^{11,15,17,21,2}$ It should be noted that the present electrical performance is still lower than the dreamed $P_{\max }=1-2 \mathrm{~W} \mathrm{~m}^{-2}$ when operating with double-chamber and/or continuous flow conditions but higher than most reported systems. ${ }^{11,14,15,17,21,24,27,34-36}$ To explain the high performance of the three-layer material of CF@Pt@biofilm,we hypothesize that the sandwiched Pt particles facilitate the electrons transfer more effectively between biofilm and electrode by stimulating the secretion of mediators. Some bacteria secrete mediating compounds such as phenazine and quinone, which are used to shuttle electron from the bacteria outer cell to the surface through mediated electron transfer mechanism. Hence, we further used electrochemical impedance spectroscopy to examine separately, the anode, the cathode, and the fuel cell. Figures $6 \mathrm{a}$, and $6 \mathrm{~b}$ depict the complexplane Nyquist plots. The profile of slightly depressed semicircles is characteristic of a charge transfer process with contribution of diffusion. This corresponds to an equivalent electrical circuit of $\mathrm{R}_{\Omega}+\mathrm{Q}_{\mathrm{CPE}} / / \mathrm{R}_{\mathrm{ct}}$ (Fig. 6c) for the double-chamber MFC, and $\mathrm{R}_{\Omega}+\mathrm{Q}_{\mathrm{CPE}} / /\left(\mathrm{R}_{\mathrm{ct}}+\mathrm{W}\right)$ (Fig. 6d) for other processes in doublechamber and air-breathing MFC. $\mathrm{R}_{\Omega}$ is the uncompensated ohmic resistance, $R_{c t}$ is the charge transfer resistance, $Q_{C P E}$ is the constant phase element, and $\mathrm{W}$ is the Warburg element. ${ }^{37,38}$ The determined ohmic resistance is $R_{\Omega}=92 \pm 4,107 \pm 3$, and $221 \pm 2 \Omega$ for CF@Pt@biofilm, CF@Pt air-cathode, and fuel cell, respectively. Taking into account the exposed areas, $\mathrm{R}_{\Omega}=1288$, and $336 \Omega \mathrm{cm}^{2}$ for CF@Pt@biofilm (exposed: $14 \mathrm{~cm}^{2}$ ), and CF@Pt air-cathode (exposed: $3.14 \mathrm{~cm}^{2}$ ), respectively. The high value of $\mathrm{R}_{\Omega}$ for the bioanode in comparison to the air-cathode results mainly from the formed biofilm (Figs. 2e vs $2 \mathrm{f}$ ). $\mathrm{R}_{\mathrm{ct}}$ was evaluated to be $19 \pm 2,146 \pm$ 1, and $153 \pm 2 \Omega$ for CF@Pt@biofilm, CF@Pt air-cathode, and fuel cell, respectively. The trend reveals that the kinetics is limited by the air-cathode. Note that with the surface area, $\mathrm{R}_{\mathrm{ct}}$ is 266 , and $458 \Omega \mathrm{cm}^{2}$ for CF@Pt@biofilm (exposed: $14 \mathrm{~cm}^{2}$ ), and CF@Pt air-cathode (exposed: $3.14 \mathrm{~cm}^{2}$ ), respectively. So the conclusion stands after the normalization. Basically, $\mathrm{R}_{\mathrm{ct}}$ is inversely proportional to the rate constant $\left(\mathrm{k}^{\circ}\right)$, which means a lower kinetics for the air-cathode in comparison to the bioanode. This fully supports quantitatively and kinetically the previous choice to normalize the current density and power density by the area of the cathode. Comparatively, in double-chamber MFC system, $\mathrm{R}_{\mathrm{ct}} \sim 10,12000$, and $12000 \Omega$ for CF@Pt@biofilm, cathode, and cell, respectively. Thus, it indicates that the air-breathing MFC is more efficient, where the reaction at the cathode is nearly two order of magnitude faster than the doublechamber. We also observed a decrease of the ohmic resistance of the CF@Pt@biofilm bioanode for double-chamber configuration, which was expected given the low current, i.e., low amount of biofilm (Figs. 4 and 5).

\section{Conclusions}

In summary, the study shows that the design of a single synthesis method to fabricate an efficient multifunctional material that has the 
ability to withstand the poisoning effects of garden compost microbial fuel cell (MFC) is doable. Specifically, a scalable electrochemical approach was tightly optimized to decorate carbon felt (CF) by platinum nanoarrays ( $\mathrm{CF} @ \mathrm{Pt})$. This $\mathrm{CF} @ \mathrm{Pt}$ simultaneously acts as an electron relay for bioanode and an abiotic electrocatalyst in doublechamber and single-chamber (air-breathing) MFC powered by the garden compost. Using batch conditions with a low metal loading, an efficient air-breathing MFC was constructed (based on a proton exchange membrane). It was able to operate tens of days. Having a large surface area and excellent electrical conductivity, this binder-free nanoscale electrode was found to effectively promote the growth of electrochemically active bacteria and facilitate the extracellular electron transfer from bacteria to their host. The electrical performance of the airbreathing MFC drastically increases in the order CF@biofilm $(\mathrm{OCV}=$ $\left.0.47 \mathrm{~V}, \mathrm{P}_{\max }=138.8 \mathrm{~mW} \mathrm{~m}^{-2}, \mathrm{j}_{\mathrm{sc}}=1.1 \mathrm{~A} \mathrm{~m}^{-2}\right)<\mathrm{CF} @$ Pt@biofilm $\left(\mathrm{OCV}=0.59 \mathrm{~V}, \mathrm{P}_{\max }=292.3 \mathrm{~mW} \mathrm{~m}^{-2}, \mathrm{j}_{\mathrm{sc}}=1.9 \mathrm{~A} \mathrm{~m}^{-2}\right)$. The present insights could inspire further developments with other metallic nanostructured particles to improve the efficiency of MFCs. This research contributes towards the design of efficient bio-electrocatalysts for the electrochemical energy conversion devices.

\section{Acknowledgments}

The authors acknowledge financial support from the Ministry of Research, Technology and Higher Education of the Republic of Indonesia (RISTEKDIKTI, Indonesia), Institut Européen des Membranes (IEM), and Université de Montpellier (France).

\section{ORCID}

Yaovi Holade (iD https://orcid.org/0000-0002-8806-568X

\section{References}

1. R. D. Milton, R. Cai, S. Abdellaoui, D. Leech, A. L. De Lacey, M. Pita, and S. D. Minteer, Angew. Chem. Int. Ed., 56, 2680 (2017).

2. P. C. Hallenbeck, M. Grogger, and D. Veverka, Electrocatalysis, 5, 319 (2014).

3. S. A. Neto, J. C. Forti, and A. R. De Andrade, Electrocatalysis, 1, 87 (2010).

4. B. Alkotaini, S. L. Tinucci, S. J. Robertson, K. Hasan, S. D. Minteer, and M. Grattieri, ChemBioChem, 19, 1162 (2018).

5. L. Zhang, J. Wang, G. Fu, and Z. Zhang, J. Clean. Prod., 276, 123203 (2020).

6. Y. Zhang, M. Liu, M. Zhou, H. Yang, L. Liang, and T. Gu, Renew. Sustain. Energy Rev., 103, 13 (2019)

7. K. L. Knoche, J. N. Renner, W. Gellett, K. E. Ayers, and S. D. Minteer, J. Electrochem. Soc., 163, F651 (2016).

8. J. B. Davis and H. F. Yarbrough, Science, 137, 615 (1962).

9. H. Liu, R. Ramnarayanan, and B. E. Logan, Environ. Sci. Technol., 38, 2281 (2004).

10. H. Liu and B. E. Logan, Environ. Sci. Technol., 38, 4040 (2004).
11. W. Yang, K.-Y. Kim, P. E. Saikaly, and B. E. Logan, Energy Environ. Sci., 10, 1025 (2017).

12. S. R. Higgins, C. Lau, P. Atanassov, S. D. Minteer, and M. J. Cooney, Electroanalysis, 23, 2174 (2011)

13. E. D. Penteado, C. M. Fernandez-Marchante, M. Zaiat, E. R. Gonzalez, and M. A. Rodrigo, Electrocatalysis, 8, 59 (2017)

14. C. Santoro, S. Rojas-Carbonell, R. Awais, R. Gokhale, M. Kodali, A. Serov, K. Artyushkova, and P. Atanassov, J. Power Sources, 375, 11 (2018).

15. C. Santoro, M. Kodali, S. Herrera, A. Serov, I. Ieropoulos, and P. Atanassov, J. Power Sources, 378, 169 (2018).

16. B. Erable, M. Oliot, R. Lacroix, A. Bergel, A. Serov, M. Kodali, C. Santoro, and P. Atanassov, Electrochim. Acta, 277, 127 (2018).

17. C. Santoro, A. Serov, L. Stariha, M. Kodali, J. Gordon, S. Babanova, O. Bretschger, K. Artyushkova, and P. Atanassov, Energy Environ. Sci., 9, 2346 (2016).

18. C. Santoro, R. Gokhale, B. Mecheri, A. D'Epifanio, S. Licoccia, A. Serov, K. Artyushkova, and P. Atanassov, ChemSusChem, 10, 3243 (2017).

19. M. A. Amirdehi, N. Khodaparastasgarabad, H. Landari, M. P. Zarabadi, A. Miled, and J. Greener, ChemElectroChem, 7, 2227 (2020).

20. B. Erable, D. Féron, and A. Bergel, ChemSusChem, 5, 975 (2012)

21. W. E. Kosimaningrum, T. X. H. Le, Y. Holade, M. Bechelany, S. Tingry, B. Buchari, I. Noviandri, C. Innocent, and M. Cretin, ACS Appl. Mater. Interfaces, 9, 22476 (2017).

22. M. Oliot, L. Etcheverry, and A. Bergel, Bioresour. Technol., 221, 691 (2016).

23. S. R. Higgins, C. Lau, P. Atanassov, S. D. Minteer, and M. J. Cooney, ACS Catal., 1, 994 (2011).

24. M. Grattieri, M. Suvira, K. Hasan, and S. D. Minteer, J. Power Sources, 356, 310 (2017).

25. M. Grattieri, N. D. Shivel, I. Sifat, M. Bestetti, and S. D. Minteer, ChemSusChem, 10, 2053 (2017).

26. E. M. Gaffney, M. Grattieri, Z. Rhodes, and S. D. Minteer, J. Electrochem. Soc., 167, $065502(2020)$

27. C. Zhang, P. Liang, X. Yang, Y. Jiang, Y. Bian, C. Chen, X. Zhang, and X. Huang, Biosens. Bioelectron., 81, 32 (2016).

28. X. Jiang, J. Hu, A. M. Lieber, C. S. Jackan, J. C. Biffinger, L. A. Fitzgerald, B. R. Ringeisen, and C. M. Lieber, Nano Lett., 14, 6737 (2014).

29. G. Gnana kumar, C. J. Kirubaharan, S. Udhayakumar, C. Karthikeyan, and K. S. Nahm, Ind. Eng. Chem. Res., 53, 16883 (2014).

30. J. Champavert, S. Ben Rejeb, C. Innocent, and M. Pontié, J. Electroanal. Chem., 757, 270 (2015).

31. C. Santoro, Y. Lei, B. Li, and P. Cristiani, Biochem. Eng. J., 62, 8 (2012)

32. Y. Holade, K. MacVittie, T. Conlon, N. Guz, K. Servat, T. W. Napporn, K. B. Kokoh, and E. Katz, Electroanalysis, 26, 2445 (2014).

33. A. Rinaldi, B. Mecheri, V. Garavaglia, S. Licoccia, P. Di Nardo, and E. Traversa, Energy Environ. Sci., 1, 417 (2008)

34. S. Singh, A. Modi, and N. Verma, Int. J. Hydrogen Energy, 41, 1237 (2016).

35. F. Mateo-Ramírez, H. Addi, F. J. Hernández-Fernández, C. Godínez, A. Pérez de los Ríos, E. M. Lotfi, M. El Mahi, and L. J. Lozano Blanco, J. Chem. Technol. Biotechnol., 92, 642 (2017).

36. M. Kodali, R. Gokhale, C. Santoro, A. Serov, K. Artyushkova, and P. Atanassov, J. Electrochem. Soc., 164, H3041 (2016).

37. A. Lasia, Electrochemical Impedance Spectroscopy and its Applications (Springer, New York, NY, United States of America) p. 367 (2014).

38. M. E. Orazem and B. Tribollet, Electrochemical Impedance Spectroscopy (John Wiley \& Sons, Inc, Hoboken, New Jersey, United States of America) p. 367 (2017). 